\title{
Nesting Behavior of Palila, as Assessed from Video Recordings ${ }^{1}$
}

\author{
Megan E. Laut, ${ }^{2,3,5}$ Paul C. Banko, ${ }^{2}$ and Elizabetb M. Gray ${ }^{2,4}$
}

\begin{abstract}
We quantified nesting behavior of Palila (Loxioides bailleui), an endangered Hawaiian honeycreeper, by recording at nests during three breeding seasons using a black-and-white video camera connected to a videocassette recorder. A total of seven nests was observed. We measured the following factors for daylight hours: percentage of time the female was on the nest (attendance), length of attendance bouts by the female, length of nest recesses, and adult provisioning rates. Comparisons were made between three stages of the 40-day nesting cycle: incubation (day 1-day 16), early nestling stage (day 17-day 30 [i.e., nestlings $\leq 14$ days old]), and late nestling stage (day $31-$ day 40 [i.e., nestlings $>14$ days old]). Of seven nests observed, four fledged at least one nestling and three failed. One of these failed nests was filmed being depredated by a feral cat (Felis catus). Female nest attendance was near $82 \%$ during the incubation stage and decreased to $21 \%$ as nestlings aged. We did not detect a difference in attendance bout length between stages of the nesting cycle. Mean length of nest recesses increased from $4.5 \mathrm{~min}$ during the incubation stage to over $45 \mathrm{~min}$ during the late nestling stage. Mean number of nest recesses per hour ranged from 1.6 to 2.0. Food was delivered to nestlings by adults an average of 1.8 times per hour for the early nestling stage and 1.5 times per hour during the late nestling stage and did not change over time. Characterization of parental behavior by video had similarities to but also key differences from findings taken from blind observations. Results from this study will facilitate greater understanding of Palila reproductive strategies.
\end{abstract}

VIDEO SURVEILLANCE of nests is a relatively common technique used to identify nest predators (Thompson et al. 1999, Farnsworth and Simons 2000, Pietz and Granfors 2000), and several studies of birds have utilized video

${ }^{1}$ U.S. Fish and Wildlife Service, USGS-BRD, and U.S. Army Garrison, Hawai' $i$, provided support for this study. Manuscript accepted 3 February 2003.

${ }^{2}$ USGS-BRD-Pacific Island Ecosystems Research Center, Kìlauea Field Station, P.O. Box 44, Hawai'i National Park, Hawai'i 96718.

${ }^{3}$ Current address: Hawai'i Natural Heritage Program, 677 Ala Moana Boulevard, Suite 705, Honolulut, Hawai'i 96813.

${ }^{4}$ Current address: The Nature Conservancy, 201 Mission Street, Fourth Floor, San Francisco, California 94105.

5 Corresponding author (phone: 808-587-8591; fax: 808-587-8599; E-mail: mlaut@hawaii.edu).

Pacific Science (2003), vol. 57, no. 4:385-392

(C) 2003 by University of Hawai'i Press

All rights reserved cameras to quantify parental behavior (Cartar and Montgomerie 1987, Challet et al. 1994, Proudfoot and Beasom 1997, Delaney et al. 1999). Use of video recordings to observe behavior at nests allows researchers to collect time budget data similar to blind observations, but more thoroughly due to the ability to stop, slow, and repeat events filmed. In addition, the movement of young chicks in the nest can be recorded with video, but usually not observed from a blind. Interference by observers is reduced because the nest does not need to be approached during data collection. The main objective of this study was to determine patterns of adult nesting behavior in the endangered Palila (Loxioides bailleui). Characterization of Palila nesting behavior at nests through the use of video recordings may help identify situations that can be solved with management, including intervening at nests with high potential to fail.

The Palila is an endangered Hawaiian honeycreeper that currently resides in $<30$ 
$\mathrm{km}^{2}$ of subalpine dry forest on Mauna Kea, Hawai'i Island (Banko et al. 2002). Population estimates during the past $20 \mathrm{yr}$ ranged from 1500 birds in 1985 to 6400 birds in 1981 (Scott et al. 1984, Banko et al. 1998). The most recent population estimate was 4800 individuals (Gray et al. 1999). Several studies of Palila nesting behavior were conducted from blinds (van Riper 1978, 1980, Pletschet and Kelly 1990; Pacific Island Ecosystems Research Center, unpubl. data) from which basic biological information was collected. Palila are monogamous breeders, although some breeding pairs had secondary male helpers attending the nest during both the incubation and nestling stages (Pratt et al. 1997, Miller 1998). Palila build a cup nest usually in māmane (Sopbora cbrysopbylla) trees, but sometimes in naio (Myoporum sandwicense) trees. Only females incubate and brood nestlings, and males feed the female at the nest and feed nestlings and fledglings (Pratt et al. 1997). A median of two eggs was laid per clutch (range, 1-3 eggs), and the nest cycle lasted a mean of 42 days from the initiation of incubation to fledging (Pletschet and Kelly 1990). The incubation stage averaged 16.6 days long, and the nestling stage averaged 25.3 days (Pletschet and Kelly 1990, Pratt et al. 1997).

\section{MATERIALS AND METHODS}

\section{Study Area}

We conducted this study during the breeding seasons (March through October) of 1991, 1993, and 1994. Nests were located by searching along transects within two established study grids on the western slope of Mauna Kea, Hawai'i ( $19^{\circ} 50^{\prime} \mathrm{N}, 155^{\circ} 34^{\prime} \mathrm{W}$ ). The dominant vegetation at the upper elevations (above $2300 \mathrm{~m}$ ) of the site was open-canopy māmane-dominant forest with a mainly grass understory, which graded into māmane-naio mixed forest at elevations below $2300 \mathrm{~m}$. All of the nests in this study were located in the māmane-dominant forest. Mean daytime temperature was $11^{\circ} \mathrm{C}$, with nighttime temperatures sometimes several degrees below $0^{\circ} \mathrm{C}$. The climate was dry, with mean annual rainfall ranging between 35 and $75 \mathrm{~cm}$ (Juvik et al. 1993).

\section{Data Collection}

A black and white video camera with an external infrared illuminator connected to an 8 -mm video recorder set at $10-\mathrm{sec}$ intervals was introduced to each nest over 1-2 days. The camera was placed under the nest tree during a natural nest recess and was moved approximately $1 \mathrm{~m}$ closer to the nest during each successive recess. Adult behavior was observed from a blind to assess if the camera was affecting behavior. If an adult appeared agitated or behaved unusually, the camera was moved to a greater distance from the nest and further attempts to introduce the camera were postponed until the next day. Additional attempts to move the camera toward the nest were done in smaller increments. In its final position, the 5 by 7 by $13 \mathrm{~cm}$ camera was approximately $30 \mathrm{~cm}$ from the nest cup. At a minimum the entire nest was in the camera's view, with up to a $6-\mathrm{cm}$ area surrounding the nest also included in the view, depending on the density of the vegetation surrounding the nest. The power source and video recorder were approximately $30 \mathrm{~m}$ from the nest tree. Nests were recorded day and night until the nestlings fledged or the nest failed. All videos contained a time/date stamp and nest identification. Each nest was visited approximately once every 3 days for regular nest checks and to change the videotape.

\section{Sampling Method}

Videos were watched on a monitor using a multispeed video player. The identity or gender of the focal bird was often not determined because color leg bands and plumage differences were not identifiable due to black-andwhite film, camera angle, or image quality. An adult bird sitting on the nest was presumed to be the female because males of this species do not incubate (Pletschet and Kelly 1990, Pratt et al. 1997). Three adult behaviors were defined as follows: (1) attentive, female incubat- 
ing eggs or brooding nestlings; (2) recess, female not on the nest; (3) visit, adult on or directly proximal to the rim of the nest. Because Palila feed young by regurgitation, visits were classified as feedings when an adult bill reached toward a nestling bill. It was not possible to identify food items or quantity of food delivered.

\section{Data Analysis}

All data were analyzed with females and males grouped into one category. We compared the percentage of time spent in attentive behavior, length of attentive bouts, the frequency of nest recesses, length of nest recesses, and provisioning rates during incubation and chick rearing using Kruskal-Wallis tests. For all tests we divided the nestling period into two stages: early ( $\leq 14$-day-old chicks) and late ( $>14$-day-old chicks). The Laysan Finch (Telespiza cantans), Palila's most closely related living relative (James and Olson 1991), has a nestling period of similar length, and growth rate is highest at day 14 (Morin 1991, 1992). In addition, Palila chicks are well feathered and begin to thermoregulate about that time (van Riper 1978).

\section{RESULTS}

We observed seven nests by video over 3 yr: two nests were observed only during the incubation stage, two only during the nestling stage, and three during both stages. We collected $742 \mathrm{hr}$ of data during the incubation stage and $1335 \mathrm{hr}$ during the nestling stage. A mean of 13.8 complete days (range, 3-25 days) was recorded at each nest during the nesting period. No helpers were identified at any of the nests in this study through observation from blinds, mist netting at nests, or video observation. Each of the two nests observed during only the incubation stage had two eggs, of which only one egg hatched.

\section{Depredation}

A feral cat (Felis catus) depredated one nest on day 2 of the nestling stage, 11 July 1991. The event occurred during the day at 1423 hours Hawaiian Standard Time. The female left the nest, and within $3 \mathrm{~min}$ the cat was at the nest, with its head in the nest cup. The cat stayed at the nest for $1 \mathrm{~min}, 10 \mathrm{sec}$ and then left. Camera angle and the size of the cat's head in relation to the nest cup prevented viewing the method of kill and consumption. The female "brooded" six times after the event, including staying on the nest overnight. The adults continued visiting the nest until 0640 hours the next day (12 July 1991). The cat evidently left little sign of its presence because discovery of the failure on a routine nest check implicated desertion due to a storm as the cause, and no disturbance of the nest was recorded.

\section{Visitation Rates}

No difference in the mean number of visits per hour by adults was detected between the early and late nestling stages $\left(X^{2}=0.33\right.$, $\mathrm{df}=1, P=0.564)$. On average, adults visited the nest fewer than two times per hour, regardless of nestling age.

\section{Nest Attendance and Recesses}

Attendance varied among the stages of the nesting cycle $\left(X^{2}=8.68\right.$, df $=2, P=0.013$, Table 1). Percentage time spent on the nest was relatively constant through the incubation stage and then gradually decreased as nestlings aged (Figure 1). However, we failed to detect a difference in the mean length of attendance bouts $\left(X^{2}=5.67, \mathrm{df}=2\right.$, $P=0.059$, Figure 2), although the average length decreased by $12.5 \mathrm{~min}$ from the incubation stage to the late nestling stage (Table 1). In contrast, mean recess length was significantly different between the three stages of the nesting cycle $\left(X^{2}=7.59, \mathrm{df}=2\right.$, $P=0.023$, Figure 2). Mean recess length remained constant through the incubation stage, then gradually increased and became more variable through the late nestling stage. No detectable difference was found in the mean number of nest recesses per hour during the incubation stage and nestling stages $\left(X^{2}=1.55\right.$, df $\left.=2, P=0.460\right)$. 
TABLE 1

Averages (SE) for Palila Parental Attendance and Behavior at Seven Nests on Mauna Kea, Hawai'i, as Assessed by Video Recordings (Comparison of Means Was Made Using Kruskal-Wallis Tests)

\begin{tabular}{lcccc}
\hline \hline & \multicolumn{4}{c}{ Stage of Nest } \\
\cline { 2 - 5 } Parameter & $\begin{array}{c}\text { Incubation Stage } \\
(n=5)\end{array}$ & $\begin{array}{c}\text { Early Nestling Stage } \\
(n=5)\end{array}$ & $\begin{array}{c}\text { Late Nestling Stage } \\
(n=4)\end{array}$ & $P$ Value \\
\hline Attendance (\% daylight hours) & $82.3(3.6)$ & $63.2(11.4)$ & $20.8(11.8)$ & 0.013 \\
Attendance bout length (min) & $27.1(1.2)$ & $20.7(6.0)$ & $14.6(1.8)$ & 0.059 \\
Recess length (min) & $6.8(1.2)$ & $12.0(4.4)$ & $48.5(12.4)$ & 0.023 \\
Recess frequency (per hour) & $2.0(0.1)$ & $2.1(0.2)$ & $1.6(0.1)$ & 0.460 \\
Adult visits (per hour) & - & $1.8(0.3)$ & $1.6(0.5)$ & 0.564 \\
\hline
\end{tabular}

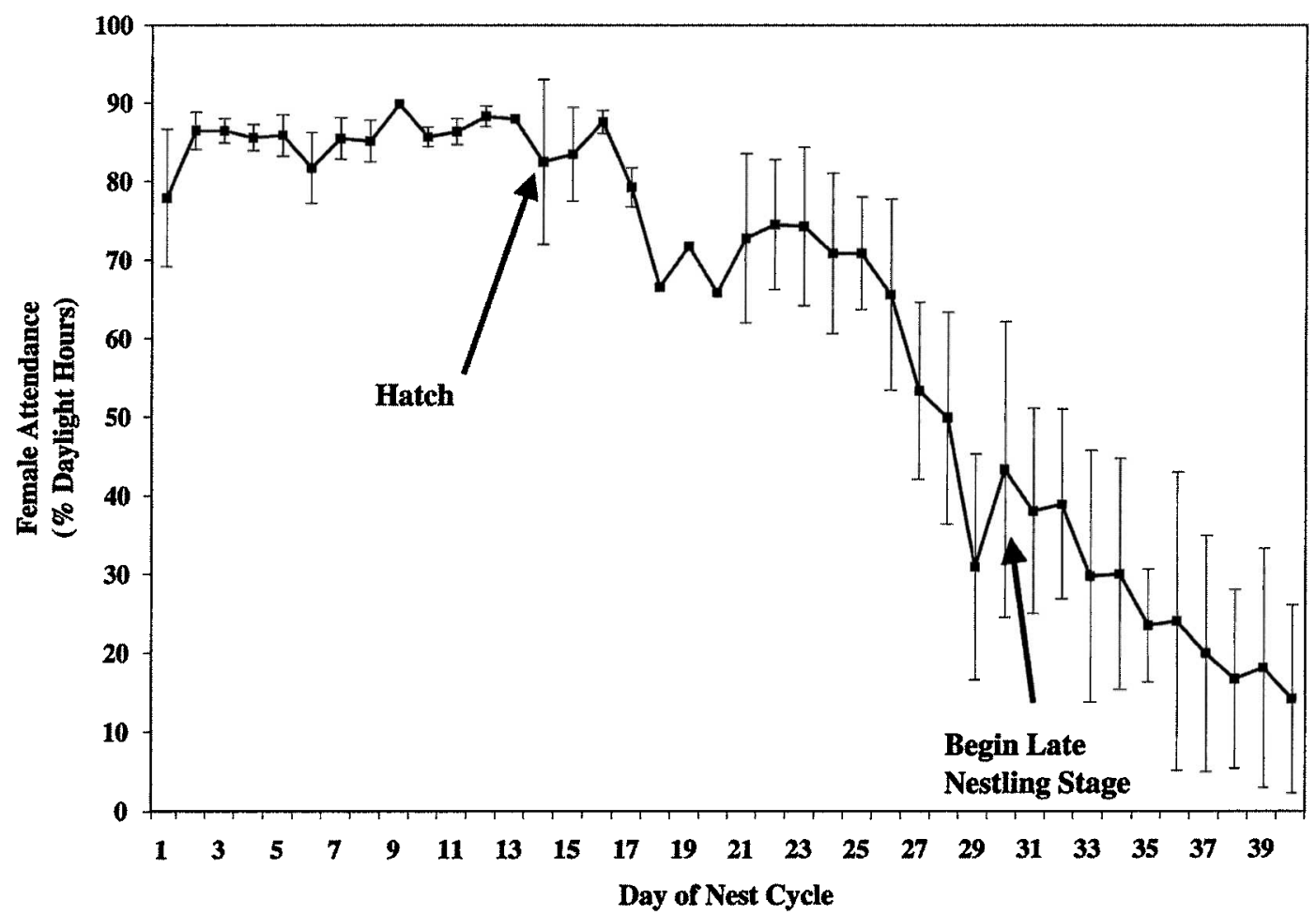

FIGURE 1. Mean percentage (SE) of daylight hours female Palila spent on the nest during the nesting cycle as observed from video recording at nests.

\section{DISCUSSION}

\section{Visitation Rates}

In our study, the mean number of adult feeding visits did not change as nestling age increased, but Pletschet and Kelly (1990) found that rates of feeding decreased later in the nestling stage. The rate of feeding we observed throughout the nestling period was similar to the lower rate they reported for the late nestling stage. Differences in sampling method could explain these contrasting re- 


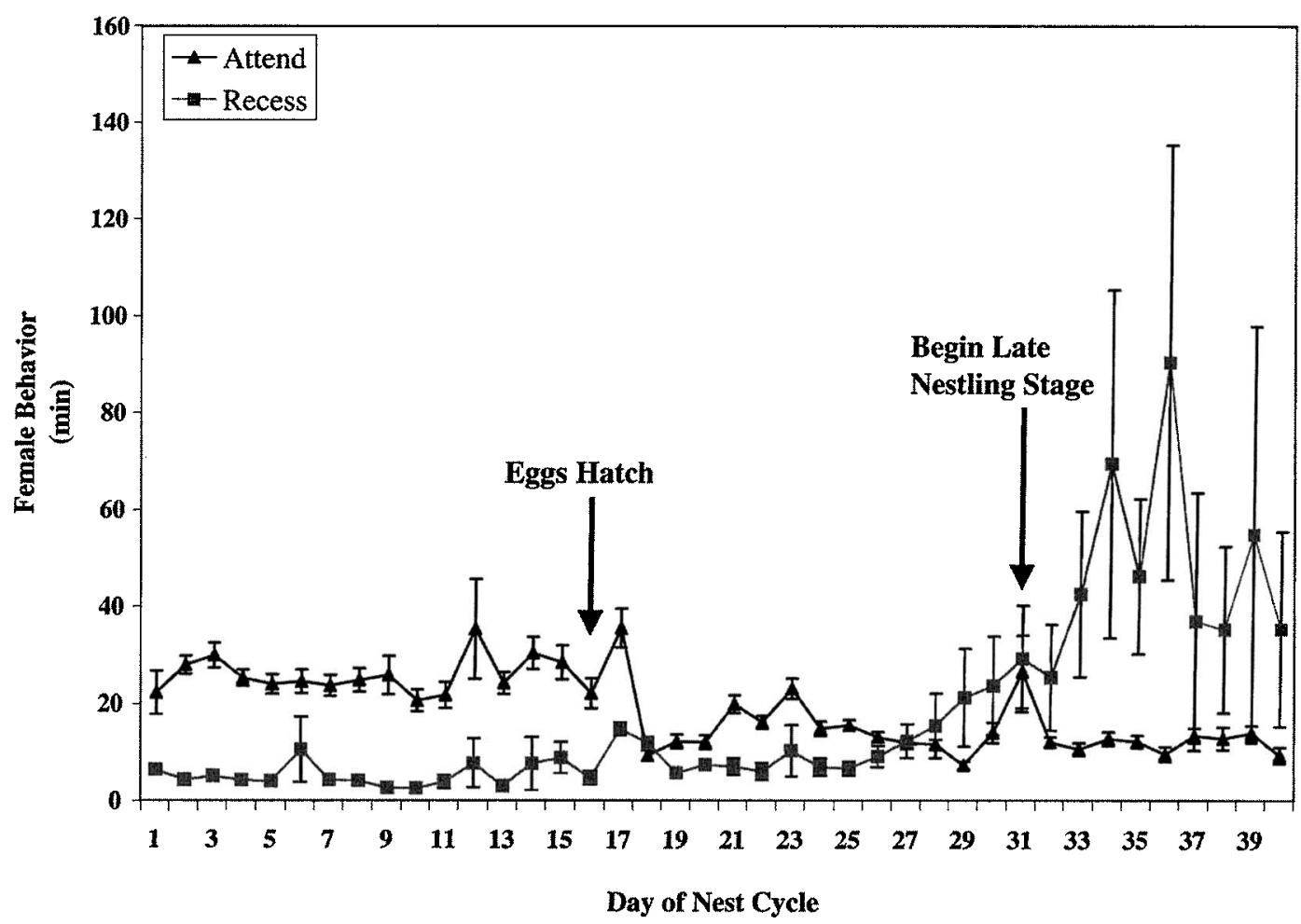

FIGURE 2. Mean (SE) length in minutes of attendance bouts (solid triangles) and nest recesses (solid squares) of female Palila as observed from video surveillance at nests.

sults: they observed nests for $1-2 \mathrm{hr}$ every other day from a blind placed $\geq 10 \mathrm{~m}$ from the nest, whereas our observation was nearly continuous. In addition, they could have classified parental visits where no chick feeding occurred as feeding events, thereby inflating estimates of feeding rates. On multiple occasions in our study, females returning from recesses looked into the nest but did not feed nestlings before beginning to brood. The heads of young nestlings are not always visible over the rim of the nest, which makes it difficult to determine whether or not food was transferred. Initial comparison of field notes and real-time video observation of $\mathrm{Pal}-$ ila nests for breeding season 1999 revealed that observers in blinds overestimated rates because views of the nest were obstructed or because the parents visited the nest very briefly without feeding nestlings (Pacific Island Ecosystems Research Center, unpubl. data). Another possible reason our findings differ could be attributed to us missing feeding events that began and ended within the 10 -sec gap in filming, although this is unlikely because most feeding events were $>20 \mathrm{sec}$.

Other studies of parental care in birds showed increased rates of feeding or increased food load by parents until just before fledging (e.g., Bedard and Meunier 1983). Growth rate of Palila nestlings is slower than that of other passerines of similar mass, which is probably due to the low rate of provisioning (van Riper 1980). Species with low predation risk grow more slowly and have longer periods of parental care while still in the nest (Ricklefs 1976). The long nesting cycle of Palila may be a result of the lack of mammalian and reptilian predators in their evolution and also of the Palila's relatively specialized diet (van Riper 1978). Compared with other honeycreepers, the Palila's nesting cycle is 
long with respect to both the incubation stage and the nestling stages (Simon et al. 2000), but is most similar to that of their closest relative, the Laysan Finch. However, Laysan Finch nestlings fledge on average 3 days earlier than Palila nestlings. Because the birds are of similar adult mass, the faster growth and earlier fledging date of the Laysan Finch could be partly attributable to a diet more variable than the Palila's (Morin 1991). Rates of food delivery to nestlings are known for several species of Hawaiian honeycreepers (Eddinger 1970, van Riper 1978, 1980, Lockwood 1994, Kepler et al. 1997, VanderWerf 1998, Simon et al. 2000). Of these species, Palila have the lowest rate of delivery for both early and late nestling phases. Feeding rates and quality of food delivered to chicks may play a major role in determining the length of the nestling phase, but this can be tested only when more data are available for other $\mathrm{Ha}$ waiian honeycreepers.

\section{Nest Attendance and Recesses}

Female Palila are more attentive to their eggs than to their chicks, presumably because embryos are more sensitive to changes in temperature than are chicks and because the male is able to provision the female more frequently before eggs hatch. Percentage of time attending the nest decreased during the nestling period because recess length increased over time. We did not detect a difference in the average length of individual attendance bouts through the nesting cycle. Pletschet and Kelly (1990) also found the length of attendance sessions to be the same for early and late stage nests, and that decreased attendance was due to longer recesses for late stage nests, not to shorter attendance bouts. Females probably do not leave young nestlings unattended for extended periods because they are unable to thermoregulate. By the time Palila nestlings are 15 days old, they are well feathered and are capable of independent thermoregulation (van Riper 1978).

Palila eggs and nestlings must be protected from low temperatures at night and high levels of solar radiation during the day. Physio- logical changes in eggs allow for adaptation to cold temperatures, whereas adjustment to heat stress is dependent on the behavior of attending adults (Zerba and Morton 1983). Because Palila are relatively heat intolerant (Weathers and van Riper 1982) and evolved in the absence of mammalian and reptilian predators, their nesting behavior is more likely to be influenced by temperature and thermoregulatory limits of adults and nestlings than by effects of predation. If heat stress affected parental behavior in Palila, we would expect to see diurnal patterns in nest attendance. No behaviors associated with heat stress were observed for females at any of the nests.

\section{Study Implications}

Depredation rates may be underestimated at nests without video surveillance. The cause of failure of the cat-depredated nest in this study was initially attributed to desertion related to a storm. The cat was at the nest less than 2 min and did not disturb the nest placement, nor was there other evidence such as blood or body parts that could have indicated to investigators the true fate of the nest. Subsequent video surveillance efforts at Palila nests have recorded additional depredation events by cats (Pacific Island Ecosystems Research Center, unpubl. data).

Video cameras are useful in quantifying activity at nests, and although the information is similar to that obtained from observers in blinds it can be more clearly interpreted and viewed repeatedly. Video recordings allow acquisition of less ambiguous data that are more detailed than those recorded from blind observations. If audio recording is incorporated into the surveillance, vocalizations and activity in the vicinity of the nest can be analyzed (e.g., a male called before female left the nest).

Our study provides a greater understanding of the variability of nesting behavior in Palila at different stages of the nesting cycle. This knowledge will aid researchers and managers in the recovery of this endangered species by providing a basis for comparison of typical nesting behavior in this species. 


\section{ACKNOWLEDGMENTS}

We thank C. Harada (deceased), J. Jacobi, L. Laniawe, and T. Pratt for assistance in the field. Thanks to G. Lindsey (deceased), S. Conant, M. Reynolds, E. VanderWerf, and an anonymous reviewer for comments on an early version of the manuscript.

\section{Literature Cited}

Banko, P. C., S. C. Hess, L. M. Johnson, and S. J. Dougill. 1998. Palila population estimate for 1997. Elepaio 58:11-15.

Banko, P. C., L. Johnson, G. D. Lindsey, S. G. Fancy, T. K. Pratt, J. D. Jacobi, and W. E. Banko. 2002. Palila (Loxioides bailleui). In A. Poole and F. Gill, eds. The birds of North America, No. 679. The Birds of North America, Inc., Philadelphia, Pennsylvania.

Bedard, J., and M. Meunier. 1983. Parental care in the Savannah Sparrow. Can. J. Zool. 61:2836-2843.

Cartar, R. V., and R. M. Montgomerie. 1987. Day-to-day variation in nest attentiveness of White-rumped Sandpipers. Condor 89:252-260.

Challet, E., C. A. Bost, Y. Handrich, J. P. Gendner, and Y. LeMaho. 1994. Behavioural time budget of breeding King Penguins (Aptenodytes patgonica). J. Zool. (Lond.) 233:669-681.

Delaney, D. K., T. G. Grubb, and P. Beier. 1999. Activity patterns of nesting Mexican Spotted Owls. Condor 101:42-49.

Eddinger, C. R. 1970. A study of the breeding behavior of four species of Hawaiian honeycreepers (Drepanididae). Ph.D. diss., University of Hawai'i at Mānoa, Honolulu.

Farnsworth, G. L., and T. R. Simons. 2000. Observations of Wood Thrush nest predators in a large contiguous forest. Wilson Bull. 112:82-87.

Gray, E. M., P. C. Banko, S. J. Dougill, D. M. Goltz, L. M. Johnson, M. E. Laut, J. D. Semones, and M. R. Wiley. 1999. 1998 Palila population census-breeding and nonbreeding censuses of the 1998 Palila population on Mauna Kea, Hawaii. Elepaio 59:33-39.
James, H. F., and S. L. Olson. 1991. Descriptions of thirty-two new species of birds from the Hawaiian Islands: Part II. Passeriformes. Ornithol. Monogr., No. 46. The American Ornithologists' Union, Washington, D.C.

Juvik, J. O., D. Nullet, P. Banko, and K. Hughes. 1993. Forest climatology near the tree line in Hawaii. Agric. For. Meteorol. 66:159-172.

Kepler, C. B., T. K. Pratt, A. M. Ecton, A. Englis, and K. M. Fluetsch. 1997. Nesting behavior of the Poo-uli. Wilson Bull. 108:620-638.

Lockwood, J. L., J. E. Greene, K. Wakelee, E. VanGelder, S. Ashe, and R. Aburomia. 1994. A description of Maui Parrotbill (Pseudonester xanthopbrys) nests and nesting behavior. Elepaio 10:61-64.

Miller, L. J. 1998. Behavioral ecology of juvenile Palila (Loxioides bailleui): Foraging development, social dynamics, and helping behavior. M.S. thesis, University of Maryland, College Park.

Morin, M. M. 1991. The breeding ecology of the Laysan Finch (Telespyza cantans) on Laysan Island. Ph.D. diss., University of Hawai'i at Mānoa, Honolulu.

- 1992. The breeding biology of an endangered Hawaiian honeycreeper, the Laysan Finch. Condor 94:646-667.

Pietz, P. J., and D. A. Granfors. 2000. Identifying predators and fates of grassland passerine nests using miniature video cameras. J. Wildl. Manage. 1:71-87.

Pletschet, S. M., and J. F. Kelly. 1990. Breeding biology and nesting success of Palila. Condor 90:1012-1021.

Pratt, T. K., P. C. Banko, S. G. Fancy, G. D. Lindsey, and J. D. Jacobi. 1997. Status and management of the Palila, an endangered Hawaiian honeycreeper, 1987-1996. Pac. Conserv. Biol. 3:330-340.

Proudfoot, G. A., and S. L. Beasom. 1997. Food habits of nesting Ferruginous Pygmy-Owls in southern Texas. Wilson Bull. 109:741-748.

Ricklefs, R. E. 1976. Growth rates of birds in the humid new world tropics. Ibis 118:179-207.

Scott, J. M., S. Mountainspring, F. L. Ram- 
sey, C. B. Kepler, J. D. Jacobi, T. A. Burr, and J. G. Giffin. 1984. Annual variation in the distribution, abundance, and habitat response of the Palila (Loxioides bailleui). Auk 101:647-664.

Simon, J. C., T. K. Pratt, K. E. Berlin, and J. R. Kowalski. 2000. Reproductive ecology of the Maui Parrotbill. Wilson Bull. 112:482-490.

Thompson, F. R., III, W. Dijak, and D. E. Burhans. 1999. Video identification of predators at songbird nests in old fields. Auk 116:259-264.

VanderWerf, E. A. 1998. Breeding biology and territoriality of the Hawaii Creeper. Condor 100:541-545. van Riper III, C. 1978. The breeding ecology of the Amakihi (Loxops virens) and Palila (Psittirostra bailleui) on Mauna Kea, Hawai'i. Ph.D. diss., University of Hawai'i at Mānoa, Honolulu. 1980. Observations on the breeding of the Palila (Psittirostra bailleui) of Hawaii. Ibis 122:462-475.

Weathers, W. W., and C. van Riper III. 1982. Temperature regulation in two endangered Hawaiian honeycreepers: The Palila (Psittirostra bailleui) and the Laysan Finch (Psittirostra cantans). Auk 99:667-674.

Zerba, E., and M. L. Morton. 1983. Dynamics of incubation in Mountain Whitecrowned Sparrows. Condor 85:1-11. 